\title{
Introduction to Special Issue on Transience
}

\section{Emerging Norms of Language Use}

\author{
Lønsmann, Dorte; Hazel, Spencer; Haberland, Hartmut
}

Document Version

Accepted author manuscript

Published in:

Journal of Linguistic Anthropology

DOI:

10.1111/jola.12168

Publication date:

2017

License

Unspecified

Citation for published version (APA):

Lønsmann, D., Hazel, S., \& Haberland, H. (2017). Introduction to Special Issue on Transience: Emerging Norms of Language Use. Journal of Linguistic Anthropology, 27(3), 264-270. https://doi.org/10.1111/jola.12168

Link to publication in CBS Research Portal

\section{General rights}

Copyright and moral rights for the publications made accessible in the public portal are retained by the authors and/or other copyright owners and it is a condition of accessing publications that users recognise and abide by the legal requirements associated with these rights.

Take down policy

If you believe that this document breaches copyright please contact us (research.lib@cbs.dk) providing details, and we will remove access to the work immediately and investigate your claim. 


\section{Introduction to Special Issue on Transience: Emerging Norms of Language Use}

\section{Dorte Lonsmann, Spencer Hazel, and Hartmut Haberland}

Journal article (Accepted manuscript)

This is the peer reviewed version of the following article: Introduction to Special Issue on Transience :

Emerging Norms of Language Use. / Lonsmann, Dorte; Hazel, Spencer; Haberland, Hartmut. In: Journal of

Linguistic Anthropology, Vol. 27, No. 3, 2017, p. 264-270., which has been published in final form at https://doi.org/10.1111/jola.12168.

This article may be used for non-commercial purposes in accordance with Wiley Terms and Conditions for Self-Archiving.

Uploaded to CBS Research Portal: January 2019 
- Dorte Lønsmann

Department of Management, Society and Communication

Copenhagen Business School

dl.msc@cbs.dk

- Spencer Hazel

School of Education, Communication and Language Sciences

Newcastle University

spencer.hazel@ncl.ac.uk

- Hartmut Haberland

Department of Communication and Arts

Roskilde University

hartmut@ruc.dk

\title{
Introduction to Special Issue
}

\section{Transience: Emerging norms of language use}

\begin{abstract}
In this introduction to the special issue, the concept of transience is introduced as a theoretical perspective and as an object of research. The perspective of transience foregrounds the temporality of norm formation, located within the practices of people on the move. The introduction suggests that it is beneficial to apply the concept of transience in order to understand processes of norm development, including those pertaining to language choice and language socialization. Working from an understanding that communities form and dissolve, we claim that it is useful to look at these processes, as it is in the process of communities coming into being that norms emerge. Transience, in spite of being ubiquitous, is not always salient for members or analysts, but to identify, fixate and theorize it as an object of study in linguistic anthropology invites new ways of conceptualizing the interdependence of language and social structure. [transience, multilingualism, workplace interaction, norm negotiation, norm development]
\end{abstract}


A key characteristic of contemporary society is the movement of people across national borders, as migrants or refugees, as tourists, or as employees of international companies. This mobility results in people coming into contact with new groups and cultures. Their challenge is often seen as that of learning how to assimilate into these new cultures, be they national, organisational or other subcultures, where part of fitting in is learning how to communicate in these new contexts. However, often the question is not simply that of how newcomers come to conform to the cultural practices of a stable community. Rather, in these conditions of transience, social configurations are continuously being formed and re-formed, as members join and leave again to join new configurations. Under these conditions, many social actors are faced with a need to adapt to new patterns of social conduct, while norms of interaction are being negotiated.

The transience we describe here is not new, but we would argue that the degree to which people move in and out of such social configurations is. We regard transience therefore as a phenomenon in the real world, the impact of which is often experienced by people in their everyday lives, e.g. when joining a new virtual project team at work or trying to fit into a new transnational student community. Transience is also a perspective that can aid anthropological linguists trying to understand current social configurations and the negotiation of communicative norms in such dynamic settings. Renan claimed that nations are built on a collective process of forgetting: "l'oubli, et je dirai même l'erreur historique, sont un facteur essentiel de la création d'une nation"1 (Renan 1882:7). In the same way, we could say that stable language communities are "imagined" in the sense of Anderson (1983). The perception of these communities as "stable" by members and researchers alike disregards their origins and historical trajectories. As a perspective, transience focuses on these trajectories, capturing the experiences of both core and marginal members, examining those on their way in or on their way out as well as new social units in the process of their forming. Transience, in spite of being ubiquitous, is not always salient for members or for analysts. However, identifying and theorizing transience as an object of study invites new ways of conceptualizing the interdependence of language and social structure by training a lens on processes of social formation as well as on the "coming into and out of being" that characterizes both individual experiences and social formations. Hence, the aim of this special issue is to introduce transience both as a research object and as a theoretical perspective.

The articles in this special issue all share a focus both on specific data and on the way that transience can be studied. All articles presented here focus on emerging norms of language conduct in multilingual and transnational workplaces. While the scope of transience studies has the potential to be much broader than this, we have adopted this particular focus here because the inherent diversity and heterogeneity in these settings make the challenges and processes related to transience that much clearer.

\section{Transience as theoretical perspective, transience as an object of study}

Much socially-informed language research is premised on identifying stability in communicative practices, on being able to provide descriptions of recurrences, patterns of use, and trends, often through orientations to or deviation from culturally established ways of conducting social life. In contrast to this, contributors to the current issue are interested in considering transience in the human social endeavour. In other words, focus is on how communities and norms come into being.

Adopting transience as a theoretical lens allows for a combined focus on time and space, both the temporality of social configurations (transience) and the movement of agents (transients). Whereas

\footnotetext{
${ }^{1}$ [Oblivion, and I would even say historical error, is an essential factor in the creation of a nation.]
} 
snapshots of particular communities and social activities, for example in Wieder's ethnomethodological study of the halfway house for paroled narcotics addicts (1974), may provide detailed accounts of a relatively stable present, what is often left unexamined is the temporality along which the observed phenomena emerge, and ultimately disappear, or are transmuted into subsequent forms. The participants too are treated as resident rather than transitory; as people who reside in the site of research, rather than as people who pass through or temporarily stop there. This special issue aims to foreground the temporality of norm formation, located within the practices between people on the move, somewhere along a timeline that has a beginning and an end. Norms emerge, gain (some) stability, and finally may disappear or are transformed into something else. Even norms that have remained in place for decades or centuries (e.g. gender norms) may change and as such show themselves to be temporally limited.

What we set out to do by adopting this perspective in our studies of social configurations and interactions, of norm formation, and of nascent indexical processes is to identify the transience embedded in social life. Our objects of study are not treated as given, but as in a state of flux, emergent, in a state of being negotiated and shaped, of becoming stabilized (or not) or of losing traction and giving way to subsequent constitutions of social orderliness.

Those social configurations, though sometimes more enduring than fashions and fads, may also come and go. Social organizations are worked up in situ by fluctuating constellations of members who mutually socialize one another into patterns of conduct deemed normatively appropriate to the social order being enacted. They may vary in lifespan from the imagined communities of nation states and military and administrative societal endeavours such as continental and global empires to the fleeting interactions between strangers whose paths momentarily intersect in a backwater of some foreign land to participate in a social configuration constituted and disbanded in the time span of a shared afternoon (for discussion, see Lemke 2000). In discussing Goffman's (1961) work on the relatively more short-term social configurations, Blommaert describes these "brief moments of tight but temporary and ephemeral groupness as aggregations of people sharing just the rules of the encounters" (Blommaert, 2017:8, italics in original). Blommaert (2017) emphasizes that people are never solely members of a single social grouping, but rather participate in a range of communities, each of which each may have a different level of stability and temporal scope. It follows that within each of these communities, members organize themselves into aggregations with shared normative expectations.

The people populating these social configurations can themselves be characterized as variably transient - people "passing through" - thereby emphasizing the relative temporality of the individual's presence and participation in the enactment of social order. Drawing on Garfinkel's (1996, following Durkheim) discussion of the idea of "lived immortal, ordinary society," individuals enter already existing social configurations in the same way we merge into an already existing traffic flow on a freeway, taking part in its orderliness. Equally we leave the freeway again later, without the traffic flow ceasing to exist as a consequence. Our contribution to the lived production of social orderliness is always temporary (albeit of a temporariness that can last as long as a lifetime). It is in our transient engagement in social configurations with relevant others that social order is produced, but it is there also that we ourselves are constituted as cultural members (Berger \& Luckman 1966:61).

With cross-border movement having become one of the defining characteristics of our time, it is to be expected that it is now that transience presents itself as a fruitful perspective to explore. In the wake of such changes to our social worlds, so too do new objects of study emerge. Although far 
from being a new phenomenon, the increased prevalence of transience throughout our social lives means that it can now be observed as a social condition, both for transitory as well as sedentary individuals, as it impacts on how they experience their social world. So whereas transience has previously held little in the way of interest during the relatively brief history of linguistic anthropology, the upsurge in transnational and transcultural mobility makes it a relevant topic to take on now. As noted by Garrett and Baquedano-López (2002) in the context of language socialization, older notions of community have become problematic because certain kinds of social and geographic boundaries, e.g. nation states, race and nationality, have diminishing relevance in today's world. Instead researchers need a way of dealing with the challenges represented by studying groups and communities that transcend these traditional borders, including transnational social phenomena. We suggest that a focus on transience will provide such a way.

\section{Socialization and norm negotiation}

In conditions of transience, social configurations continuously change as participants join and leave again to participate in new configurations. One consequence of this fluidity is that shared norms cannot be assumed to be in place. It follows that norm negotiation and norm development are basic conditions of living or working in a transient social space. In the traditional view of language socialization, norms are assumed to be relatively stable with new members being inducted into the existing norms of a culture or community through interaction with more established members, e.g. parents or co-workers. In transient social configurations such as the transient multilingual communities described by Mortensen (this issue), there may not be stable norms for newcomers to be socialized into. Instead, these are settings where "diversity is the norm, and where distinctions between newcomers and hosts continually change" (Goebel 2010:203). Consequently, the socialization process is not only continuous, but multidirectional. As Lønsmann (this issue) shows, in transient settings the introduction of a new member into the group is not only an occasion for the passing on of existing norms, but also for the construction and implementation of new norms.

Even under conditions of transience and fluidity, however, history matters and existing structures matter. While participants in transient settings "do not share the same trajectories of socialization" (Goebel 2010:223), everyone brings along their own personal history and experience. Along with the setting and the activity, these heterogeneous histories and competences influence the processes of norm negotiation and norm recognition (see Hazel this issue, Millar this issue). One way that such histories influence norm negotiation is in the recontextualisation of existing semiotic registers in new settings (Goebel 2010). Another is in the way that existing language competences influence norms of language choice, as shown e.g. by Moore (this issue).

\section{A new "super"-fad?}

This is a time for fads, as Reyes (2014) has pointed out in her article on the adoption of "super-newbig" perspectives and terminology in linguistic anthropology. Vertovec (2007) came with a modest proposal to look at multiethnic communities like certain London boroughs with the view that they are not just diverse, but display a second-order diversity, something that has been called a "diversity of diversities" in several disciplines. He coined the term "super-diversity" for what he found, and the term has gone rampant ever since in studies of linguistic diversity. One argument levelled against the usefulness of the concept is that superdiversity is not really as new or groundbreaking as the proponents of the term would have us think (Pavlenko in press). This "diversity of diversities" has characterized linguistic communities elsewhere for a long time (one can take the Indian 
subcontinent as an example), but what is new is that the increased globality (Beck 2000, Haberland 2009) in migration and spread of languages has brought superdiversity not just to London, but to Great Britain and the rest of Europe, creating the impression (in Europe) that we are witnessing something new on a global scale. However, as Reyes (2014) argues, the world has not become more diverse or superdiverse; instead researchers have simply started focusing more on these particular patterns of diversity.

What we are proposing in this special issue could, of course, also be taken to be a new fad, but we are advancing a more modest proposal than the proponents of superdiversity. Although we think that transience is a useful concept in analyzing particular sociolinguistic processes in contemporary contexts, we do not, as argued above, claim that it is a new phenomenon. By taking up the concept of transience introduced by Goebel (2010), de Sapio (2013) and Mortensen (2013), we do not argue that the world has necessarily become more transient. Rather we suggest that it is beneficial to apply the concept of transience in order to understand the inherent flux and instability in the ways that communities form, evolve and eventually change into new constellations. Some of these communities might never develop a set of stable mutual assumptions between their members; others may develop orderliness in their interactions, if only to help them through their "management of ignorance" (Blommaert and Rampton 2011:7). Sharedness is never total, as Hannerz points out; there is a temporal dimension to diversity: "Rather than concentrating on what is persistent, we must ask, furthermore, how variations in temporality are built into cultural process" (Hannerz 1992:46). Even though we do not exactly know what others expect of us and how they understand our actions, verbal and otherwise, we rarely find ourselves completely out of our depth, since practices can emerge (and vanish) rather rapidly, yet be established along the lines of social norms from other social configurations.

\section{Transience and multilingualism}

Where studies of multilingualism up until the end of the $20^{\text {th }}$ century tended to focus on relatively stable patterns of language choice and language alternation in relatively stable speech communities, since then researchers of multilingualism have increasingly turned their attention to the use of diverse linguistic resources in (often) urban settings and smaller communities of practice. The shift away from bilingualism and towards repertoires of linguistic resources is very visible in the large number of empirical investigations and theoretical discussions as well as in the large number of terms coined to capture this new orientation. From language crossing (Rampton 1995, 1999) to metrolingual practice (Otsuji and Pennycook 2013), polylingual languaging (Jørgensen 2008), translanguaging (García 2009, García and Li 2014) and transidiomatic practice (Jacquemet 2005), these newer perspectives emphasize the influence of global flows of migration and communication on language use. However, even while these $21^{\text {st }}$ century perspectives on multilingualism share a view of linguistic norms and ideologies as negotiated in interaction, they do not typically focus on how these norms come into being, and how the fluid and changing conditions of contemporary life impact on these processes of norm formation. In contrast, the present special issue aims to bring this focus on the role of transience for the emergence of social and linguistic norms to the field of multilingualism studies.

There is no direct connection between transience and multilingualism; transience and linguistic diversity are not always and necessarily experienced in the same contexts. All the authors in the issue specialize in the study of multilingual workplaces and first came together for a workshop on 
language in the transnational workplace. ${ }^{2}$ While we did not set out to study transience, ideas about transience emerged from this common focus. Subsequently, our ideas about transience have also been challenged by studying these settings. How does one recognize it? How does one capture processes of change? Which methodological approaches best allow for claims of norm development to be supported, and which do not? The purpose of this special issue is to gather together data and analyses to further develop and explore the notion of transience. The multilingual workplace is the empirical focus of the studies included here, which cover international corporations, international universities and an international theatre company. Furthermore, we would argue that the inherent cultural and linguistic diversity in these multilingual and transnational workplaces makes for an ideal site to study norms of language use as they emerge in interaction.

The work in this special issue is positioned in the overlapping space between interactional sociolinguistics and linguistic anthropology, in particular with respect to notions of community, indexicality, norm development, language choice and language ideologies. The empirical studies also draw on a range of research paradigms and theories, including interactional studies, plurilingualism, language socialization and language ideologies. We see this heterogeneity as a strength of the special issue as it allows us to explore our core topic - transience - from several angles.

The first article by Mortensen introduces the notion of transient multilingual communities as a new field of investigation for linguistic anthropology and sociolinguistics. Mortensen argues that by focusing on the empirical phenomenon of transient communities, we can contribute to the paradigm interested in sociolinguistic change (Coupland 2014) where focus is not just on linguistic changes, but also on changing relationships between language and society. Mortensen outlines the notion of transient multilingual communities and their three defining characteristics: They are emergent, activity-based and linguistically and culturally heterogeneous. Using examples from his work on language choice and language ideologies in international higher education, Mortensen clarifies how the transience of such settings influences the negotiation of norms for language choice as well as the negotiation of language attitudes and language ideologies.

Moore's article takes us to a multilingual university in Catalonia, looking at how the internationalization of higher education creates a transient setting in which language choice needs to be negotiated, sometimes on the spot. Moore highlights how participants mobilize their plurilingual competences to achieve intercomprehension, and the analysis shows how norms are negotiated in interaction. In particular, Moore reveals how participants construct the use of a plurilingual medium as preferable to instantaneous interpretation or English as a lingua franca. By focusing on the simultaneous use of intercomprehensible Spanish, Catalan, French and Italian used as resources in receptive multilingualism, Moore also emphasises that internationalization of higher education does not necessarily lead to more English, but could also promote increased linguistic diversity in practice.

Millar's article is based on interview data from three Danish multinational companies. Her study focuses on corporate sociolinguistic economies of English, including the individual sociolinguistic economies of employees. The article explores the values given to multilingual communicative practices, particularly communication accommodation practices. While the ideology of English as the natural lingua franca has a strong position in these companies, Millar's study also shows how

${ }^{2}$ At the 2013 Language and Super-Diversity conference at the University of Jyväskylä, Finland. 
the perceived value of English fluctuates as it is contingent on contexts, tasks and communicative goals. The study finds that the position of English in the sociolinguistic economies of these international companies can be linked with transient conditions both because English is seen as a language that is useful for international communication across settings and because English is seen as a stabilizing force in settings characterised by fluidity and mobility. As such the study emphasises the link between the language ideology of English as the natural lingua franca in the corporate world and transient conditions.

Like Millar, Lønsmann's article also focuses on an organizational context where language choice and language socialization are linked with the strategic goals of the organization. Lønsmann describes a particular strategic intervention in a corporate company in Denmark. Whereas newcomers are commonly socialized into the stable language norms and practices of the community they enter into, here members of staff with limited or no Danish proficiency are deliberately introduced into the workplace in order to occasion an increased use of English among the Danish workforce. The underlying rationale is to encourage staff to adopt a "global mindset," and it is change, rather than stability that constitutes the end goal. The study reports on how newcomers are used as catalysts for change, as long-term employees are induced to adopt new language practices, while at the same time newcomers themselves are socialized into the norms, values and practices of the existing workplace culture. The article also problematizes the role of the catalyst as on the one hand a relatively high-status position in the workplace, but on the other also an exposed position which entails risks of exclusion and marginalization.

The final article of the special issue is set in a multilingual workplace in the world of arts. Based on longitudinal audio-visual recordings of the rehearsals of one theatre company ensemble, Hazel focuses on the theatre ensemble as a transient project community. Introducing the notion of "langscaping," i.e. members' exploring each other's linguistic repertoires and socio-cultural histories, Hazel investigates how linguistic practices in the ensemble develop over time. From the initial informal language policy focusing on English, the participants develop a preference for using an expanded set of linguistic resources, allowing members to draw on their wider language repertoires. Hazel's analysis highlights how language choice becomes not only increasingly multilingual and complex, but also less stabilized, rather than evidencing increased stability over time.

The issue is wound up by an Epilogue by Jo Angouri. Here, she draws together thematic strands from across the studies, in order to evaluate the path taken, while offering a discussion of where this work takes us, and what directions to explore in the future.

Anderson, Benedict

\section{References}

1983 Imagined Communities. London: Verso.

Beck, Ulrich

2000 What is Globalization? Oxford: Polity Press [in German, 1997].

Berger, Peter L., and Thomas Luckmann

1966 The Social Construction of Reality. London: Allen Lane.

Blommaert, Jan

2017 Society through the Lens of Language: A New Look at Social groups and Integration.

Tilburg Papers in Cultural Studies. Tilburg: Tilburg University.

Blommaert, Jan, and Ben Rampton

2011 Language and Superdiversity. Diversities 13(2):1-21 
Coupland, Nikolas

2014 Sociolinguistic Change, Vernacularization and Broadcast British Media: Mediatization and Sociolinguistic Change. In Mediatization and Sociolinguistic Change. Jannis

Androutsopoulos, ed. Pp. 67-96. Berlin: Mouton de Gruyter.

de Sapio, Joseph

2013 Transient Communities: Travel, Knowledge, and the Victorian Railway Carriage, 1840-90.

Mobilities 8(2):201-219.

García, Ofelia

2009 Bilingual Education in the 21st Century: A Global Perspective. Malden, Mass. and Oxford:

Basil Blackwell.

García, Ofelia and Li Wei

2014 Translanguaging: Language, Bilingualism and Education. Basingstoke: Palgrave

Macmillan.

Garfinkel, Harold

1996 Ethnomethodology's Program. Social Psychology Quarterly 59(1):5-21.

Garrett, Paul B., and Patricia Baquedano-López

2002 Language Socialization: Reproduction and Continuity, Transformation and Change.

Annual Review of Anthropology, Pp. 339-361.

Goebel, Zane

2010 Identity and Social Conduct in a Transient Multilingual Setting. Language in Society

39(2):203-240.

Goffman, Erving

1961

Haberland, Hartmut

2009 English - The Language of Globalism? Rask. Internationalt tidsskrift for sprog og

kommunikation 30:17-45.

Hannerz, Ulf

1992 Cultural Complexity: Studies in the Social Organization of Meaning. New York: Columbia

University Press

Jacquemet, Marco

2005 Transidiomatic Practices: Language and Power in the Age of Globalization. Language \&

Communication 25(3):257-277.

Jørgensen, Jens Norman

2008 Polylingual Languaging around and among Children and Adolescents. International Journal

of Multilingualism 5(3): 161-176.

Lemke, Jay L.

2000 Across the Scales of Time: Artifacts, Activities, and Meanings in Ecosocial Systems. Mind,

Culture and Activity 7(4):273-290.

Mortensen, Janus

2013 Notes on English Used as a Lingua Franca as an Object of Study. Journal of English as a

Lingua Franca 2(1):25-46.

Otsuji, Emi, and Alastair Pennycook

2013 Unremarkable Hybridities and Metrolingual Practices. In The Global-Local Interface and

Hybridity: Exploring Language and Identity. Rani Rubdy and Lubna Alsagoff, eds. Pp. 83-99.

Bristol: Multilingual Matters.

Pavlenko, Aneta

In press Superdiversity and why it isn't: Reflections on terminological innovation and academic branding. In Sloganizations in language education discourse. S. Breidbach, L. Küster \& B. 
Schmenk, eds. Bristol, UK: Multilingual Matters.

Rampton, Ben

1995 Crossing: Language and Identity among Adolescents. London: Longman.

Rampton, Ben

1999 Crossing. Journal of Linguistic Anthropology 9(1-2):54-56.

Renan, Ernest

1892 Qu'est-ce qu'une nation? [What is a nation?] Paris: Calmann Lévy.

Reyes, Angela

2014 Linguistic Anthropology in 2013: Super-New-Big. American Anthropologist 116(2):366378.

Vertovec, Stephen

2007 Super-Diversity and its Implications. Ethnic and Racial Studies 29(6):1024-1054.

Wieder, D. Lawrence

1974 Telling the Code. In Ethnomethodology: Selected Readings. Roy Turner ed. Pp. 144-172.

Harmondsworth, UK: Penguin. 